\title{
Wastewater reuse in agriculture sector: resources management and adaptation in the context of climate change: case study of the Beni Mellal-Khenifra region, Morocco
}

\author{
Elhousna Faouzi ${ }^{*}$, Abdelkrim Arioua, Ismail Karaoui, Kamal Ait Ouhamchich, and Driss \\ Elhamdouni \\ Earth sciences department, Sultan Moulay Slimane University, Faculty of Sciences and Techniques \\ Beni Mellal, Morocco
}

\begin{abstract}
Recent climate change effects worsened water scarcity in Morocco and forced the country to seek alternative water resources such as domestic and industrial wastewater. In this context, we assessed the treatment efficiency of wastewater treatment plants (WWTP) of the BeniMellal-Khenifra region based on physicochemical and biological parameters. Vegetation cover evolution near WWTPs was also analysed using satellite images (Landsat TM and OLI). Six WWTP were evaluated based on treated water quality and a survey of nearby farmers and residents. Results showed treated wastewater is in line with Moroccan standards, and can be reused for irrigation and aquaculture without harmful effects. The survey pointed to the Boujaad WWTP as a model in the region. The vegetation cover evolution before and after WWTP existence showed an important improvement of cultivated lands. As a conclusion, wastewater reuse will allow the BeniMellal-Khenifra region to secure agricultural irrigation to safeguard freshwater quantities and quality despite climate change.
\end{abstract}

\section{Introduction:}

Rapid urbanization and climate change increase pressure on the availability of freshwater resources in Morocco [1]. Water scarcity is particularly acute in semi-arid and arid zones, because of the growth resulting from the accelerated demographic and economic development in many Moroccan cities [2]. Limits to water resources availability is not only caused by limited quantities, but also degraded quality resulting from contaminants generated by domestic, industrial and agriculture activities [3]. Therefore, it is necessary to consider unconventional water resources such as wastewater to meet high water demand by different sectors, and to recover the significant wastewater discharged directly into nature without any treatment[4]. Wastewater treatment becomes the primary concern as it is associated to the issues of population health and environment degradation. Wastewater can

\footnotetext{
*Corresponding author: elhousna.faouzi@usms.ac.ma
} 
be used for sectors with quality requirements below human consumption standards, such as agriculture, aquaculture and other social activities[5].

Remotely sensed data has been applied worldwide in land cover classification and monitoring on a regional or global scale [6]. It is particularly important when field data is unavailable, or hard to retrieve [7]. Remote sensing techniques provide reliable information on monitor wastewater treatment plants contribution in vegetation cover development. Landsat TM, OLI images were used for their potential application in identifying the land cover classification and the hydrographic system[8]. A selected time-series of twelve satellite images over the period from 2008 to 2018 were used to map the vegetation cover in the study area (near WWTPs). Those images were obtained under clear sky conditions to reduce induced effect by atmospheric disturbances. Support vector machine (SVM) classification was used to estimate the vegetation cover evolution in areas close to WWTPs.This result will present the importance of wastewater reuse in the agriculture sector, and to highlight the contribution of remote sensing applications in evaluating vegetation cover.

The BeniMellal-Khenifra region has 13 wastewater treatment plants, most of them in poor condition or under construction[9]. The poor condition of WWTPs leads to malfunction, that in turn creates environmental issues, as the treated water is either reused in agriculture despite its high pollution load, or discharged directly into nature to pollute groundwater and surface water. Municipalities in the BeniMellal-Khenifra region cities are using natural lagoon ssystem, due to its efficient process, low economic cost, and adapted to semi-arid arid climate conditions. This lagoons system is largely appreciated in its efficiency in small towns, and recommended for hot climate conditions [10]. lagoon system technique is considerable efficient in eliminating pathogenic germs and ensure a better reuse of wastewater in agriculture sector [11].

\section{Materials and methods}

\subsection{Study area}

The BeniMellal-Khenifraregion is located in the center of central part in Morocco. It is 240 $\mathrm{km}$ far away from Moroccan capital Rabat [12]. This region is characterised by four large natural landscape: the mountain ranges, piedmont, the Khouribga phosphates plateau, and the Tadla Plain [13]. This region is formed byBeniMellal, Azilal, Fkih Ben Salah, Khenifra, and Khouribga provinces (Figure1) [14]. Climate in the study area is arid to semi-arid. The average annual rainfall is around $100 \mathrm{~mm}$ in the arid area and the 600 in humid area. The average temperature is $18^{\circ} \mathrm{C}\left(40^{\circ} \mathrm{C}\right.$ in summer and $-3,5^{\circ} \mathrm{C}$ in winter)[15]. 


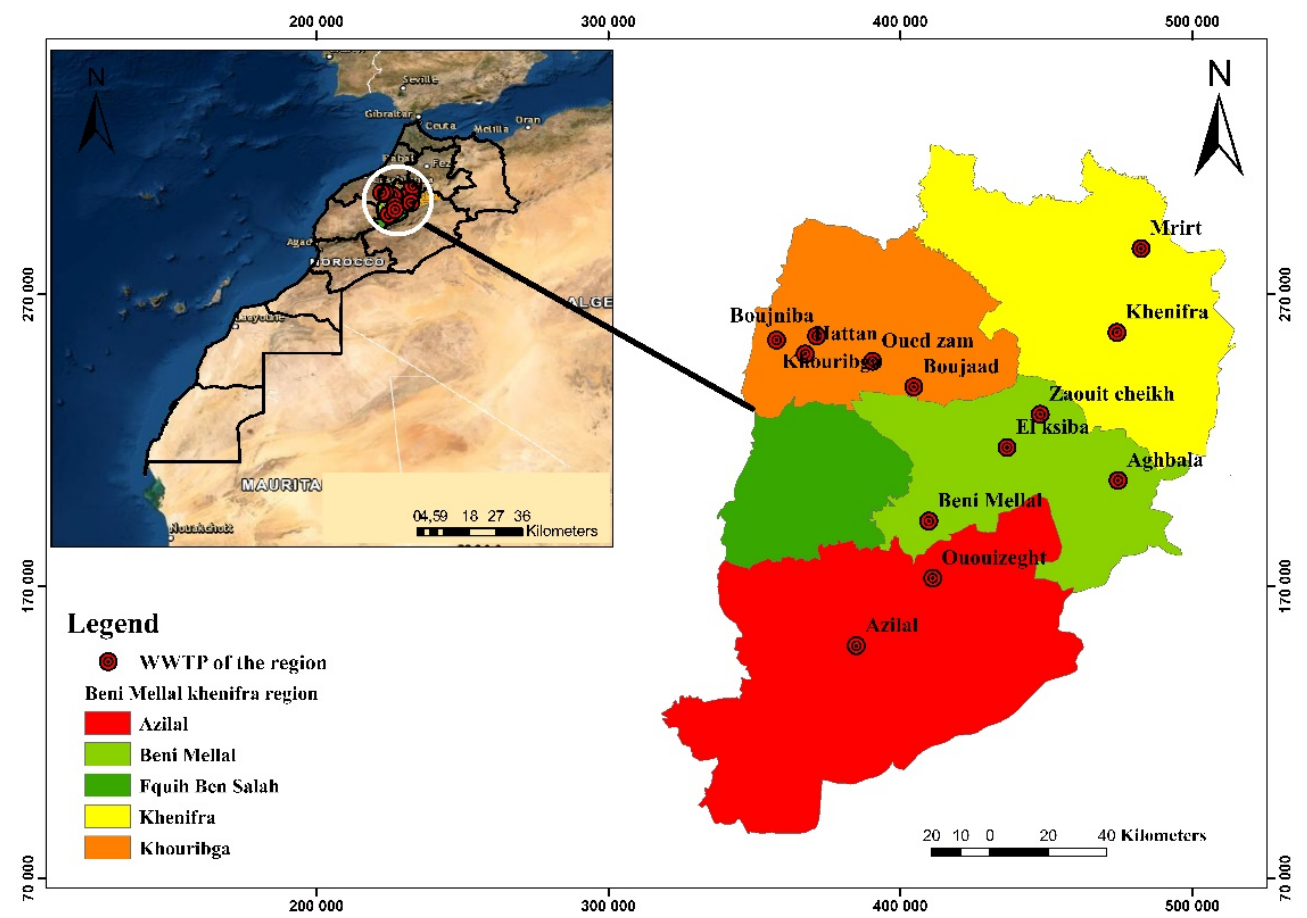

Fig. 1:Geographic location of WWTP in the BeniMellal-khenifra region.

\subsection{Methods}

The physico-chemical and microbiological composition of water is essential to identify possible reuse of treated wastewater[16]. For this purpose, raw and treated wastewater quality at six WWTPs in the study area was analysed to reveal associated shortcoming and anomalies at each treatment plant. Wastewater samples were taken upstream and downstream of each treatment plant during field visits. Raw and treated urban wastewater samples were collected from the inlet and outlet points for each WWTP during two periods, high quantity of wastewater arriving into the station (morning and evening) and low one (noon hours). Farmers and residents close WWTPs were surveyed. Satellite images were downloaded from the Internet. Applying the Supervised classification SVM, this method aims to find the optimal result with limited information provided by a small set of samples[17].

\subsubsection{Water quality parameters}

The following physical and chemical parameters have been measured at field(electrical conductivity, temperature, salinity, and $\mathrm{pH}$ ), while the rest (Biochemical oxygen demand, chemical oxygen demand, total suspended solids, nitrates, nitrites, ammonium, orthophosphates, and sulphate) were analysed at Hydraulic Basin Agency laboratory following the AFNOR Moroccan standards [18]. The Moroccan standards for $\mathrm{NH}_{4}{ }^{+}, \mathrm{NO}_{2}{ }^{-}$and $\mathrm{PO}_{4}{ }^{3-}$, are not set for irrigation purpose, as these parameters are generally absorbed during the treatment process [19].

The sampling procedure is done under favourable conditions, in accordance with Moroccan standard procedure, while adding fixing reagents, and taking all the necessary precautions during the transport of the samples (storage in ice). 
Electrical conductivity and salinity are good indicators for substances assessment [20]. Both parameters are strongly linked, and are originally coming from a natural or anthropogenic source. Controlling the salinity of irrigation water is of major importance, whether for natural waters or for wastewater [21].

Water salinity is calculated based on electrical conductivity and in situ temperature, by applying the following formula [22].

$$
\sum_{i=0}^{5}\left\{\left[a i+\left(\frac{t-15}{1+k(t-15)}\right) b i\right] R t^{\left(\frac{i}{2}\right)}\right\}[22]
$$

With: $R t=\frac{C s, t, p}{42.914 r t}$ and $r t=\sum_{i=0}^{4} C_{i t}{ }^{i}$

S: Salinity $(\mathrm{g} / \mathrm{L})$;

Cs, t, p: Electrical conductivity $(\mathrm{ms} / \mathrm{cm})$;

$\mathbf{T}$ : Temperature in ${ }^{\circ} \mathrm{C} ; \mathrm{a}_{\mathrm{i}}, \mathrm{b}_{\mathrm{i}}, \mathrm{c}_{\mathrm{i}}$ and $\mathrm{k}$ are dimensionless observations

\subsubsection{Survey}

The survey is aiming to identify the impact of wastewater treated on near population health, social economy, types of adopted cultures, and the WWTP impact on their crop yield. However, a survey targeting individual farmers was conducted in all the exposed and unexposed areas near WWTPs. This survey is dedicated to collectinformation on agricultural crops production trends during last few years (after the existence of WWTP), the impact of wastewater reuse in agriculture sector,environment, public health,wastewater benefits on irrigation, quantity of fertilizer used, types of cultures irrigated by wastewater, and the farmer's suggestion for the current management of their wastewater.

Based on a preliminary survey, the treated and untreated wastewater are both used for irrigation in thestudy area. Most of farmer's in this study area using partly treated water for plots irrigation without a fertilizer because this water contains a significant amount of nutrients.

The collected survey information/responsewerebased on a simple statistical analysis, summarized in figure 3.

\subsubsection{Crop yield and WWTP performance evaluation using satellite imagery}

Satellite images (Landsat TM, OLI) were used to evaluate the evolution of vegetation, and to determinate WWTP performance at upstream and downstream of all treatment plants. Landsat images were obtained from United States Geological Survey (USGS) Earth Explorer portal (https://earthexplorer.usgs.gov). A subset of the images was selected based on a certain number of factors: availability and the atmospheric conditions during the images acquisition were used. Only images captured during the summer time were used, as the climate is the drier so there is no much evaporated water in the atmosphere. The LS5 images are characterized by seven spectral bands width a spatial resolution of $30 \mathrm{~m}$ for Bands 1 to 5 and 7. The spatial resolution for Band 6 (thermal infrared) is $120 \mathrm{~m}$, andLS8 images consist of multispectral and thermal bands, and a panchromatic band with higher spatial resolution $(15 \mathrm{~m})[23]$.The images were georeferenced using the World Geodetic System 1984 datum (WGS-84) and the Universal Transverse Mercator (UTM) projection (Table1).Although the captured images were processed by applying all necessary operations: radiometric and atmospheric corrections, using FLASH the module. Supervised classification (SVM) was applied to detect the vegetation cover evolution before and after WWTP existenc ein the study area. SVM algorithm is a new general learning algorithm based on statistical theory. 
Table 1.Landsat image's metadata.

\begin{tabular}{|c|c|c|}
\hline Metadata & Image (2008) & Image (2018) \\
\hline Sensor & TM & OLI \\
\hline $\begin{array}{c}\text { Output } \\
\text { format }\end{array}$ & GEOTIFF & GEOTIFF \\
\hline Day/Night & Day & Day \\
\hline Cloud Cover & 0 & 0 \\
\hline Projection & UTM & UTM \\
\hline Datum & WGS84 & WGS 84 \\
\hline
\end{tabular}

\section{Results and Discussion}

According to water intended for irrigation quality standards in Morocco [24], we noted that the parameters $(\mathrm{pH}$, temperature, BOD(Biological Oxygen Demand), conductivity) of treated wastewater are comply with standards. Indeed, the $\mathrm{pH}$ values of all the WWTP in the region spanned between 6.5 and 8.5 as a limit value for irrigation water quality, The Moroccan standard has set an interval of 6.5 and 8.5 for $\mathrm{pH}$ as permissible values [16]. The study results observed that the $\mathrm{pH}$ of the treated wastewater was suitable for irrigation, explained by a neutral $\mathrm{pH}$ around 7.5.

The electrical conductivity (EC) and salinity values were within the limit values for treated wastewater quality intended for irrigation[24]. The limit value is $3 \mathrm{mS}^{-\mathrm{cm}^{-1}}$ for conductivity and $7.68 \mathrm{~g} / \mathrm{L}$ for salinity, explains slight to moderate restriction use of treated wastewater.

It is imperative that farmers first ensure the physical quality of their soil and the proper drainage. Poor drainage could trigger accumulation of salts in the root zone and limit the availability of water in the soil for crops. The risks of soil salinization resulting from irrigation with such water present a criterion detrimental to its quality and can be considered harmful for sensitive crops, particularly at the study area where evaporation is high.

Temperature values are also lower than the Moroccan irrigation standard fixed on 35 ${ }^{\circ} \mathrm{C}$. The high conductivity (salinity indicator) concentration was caused by high evaporation at semi-arid climate. However, the values recorded after treatment were accepted for Moroccan standard controlling irrigation water, which imposes a maximum of $3000 \mu \mathrm{S} /$ $\mathrm{Cm}$ at $25^{\circ} \mathrm{C}$.

The concentrations of chemical oxygen demand(COD)in the Azilal, Zaouit Echcheikh and Ouaouizeght WWTPs are above the standard set here at $250 \mathrm{mgO}_{2} / \mathrm{L}[25]$. The treated wastewater from the other three remaining WWTPs was intended to be reused in irrigation. In addition, the concentration of the $\mathrm{BOD}_{5}$ wastewater taken from the WWTP is not suitable for irrigation. Indeed, the limit of $120 \mathrm{mgO}_{2} / \mathrm{L}$ set by the Moroccan standard is not respected here [25].

The total suspended solid (TSS) content is $90.9 \mathrm{mg} / \mathrm{L}$ at El Ksiba WWTP outlet, which was considered suitable for irrigation use. Indeed, the quality standards referenced for wastewater intended into irrigation indicated that the limit values were around $2000 \mathrm{mg} / \mathrm{L}$ for gravity irrigation and $100 \mathrm{mg} / \mathrm{L}$ for spray irrigation[24]. The other WWTP with a high 
TSS load reaching around $250 \mathrm{mg} / \mathrm{L}$ were greater than the maximum allowable value. In fact, using a treated wastewater with its high load need to take precaution to avoid clogging of the soil porosity and low permeability.

The $\mathrm{NO}_{3}{ }^{-}$concentrations ranging between $1.11 \mathrm{mg} / \mathrm{L}$ and $4.09 \mathrm{mg} / \mathrm{L}$ at the outlet, hence, it was considered suitable for irrigation purpose. Nitric nitrogen, which is frequently used in agricultural fertilizers, is often a pollutant of groundwater therefore must be closely monitored. In our study area, where farmers used a low quantity of pesticide, the nitrate concentration was far from permissible value of $30 \mathrm{mg} / \mathrm{L}$.

The acceptable sulphate values for treated wastewater intended for irrigations was fixed at $250 \mathrm{mg} / \mathrm{L}$, meaning that all our collected samples were suitable and can be reused for irrigation. 


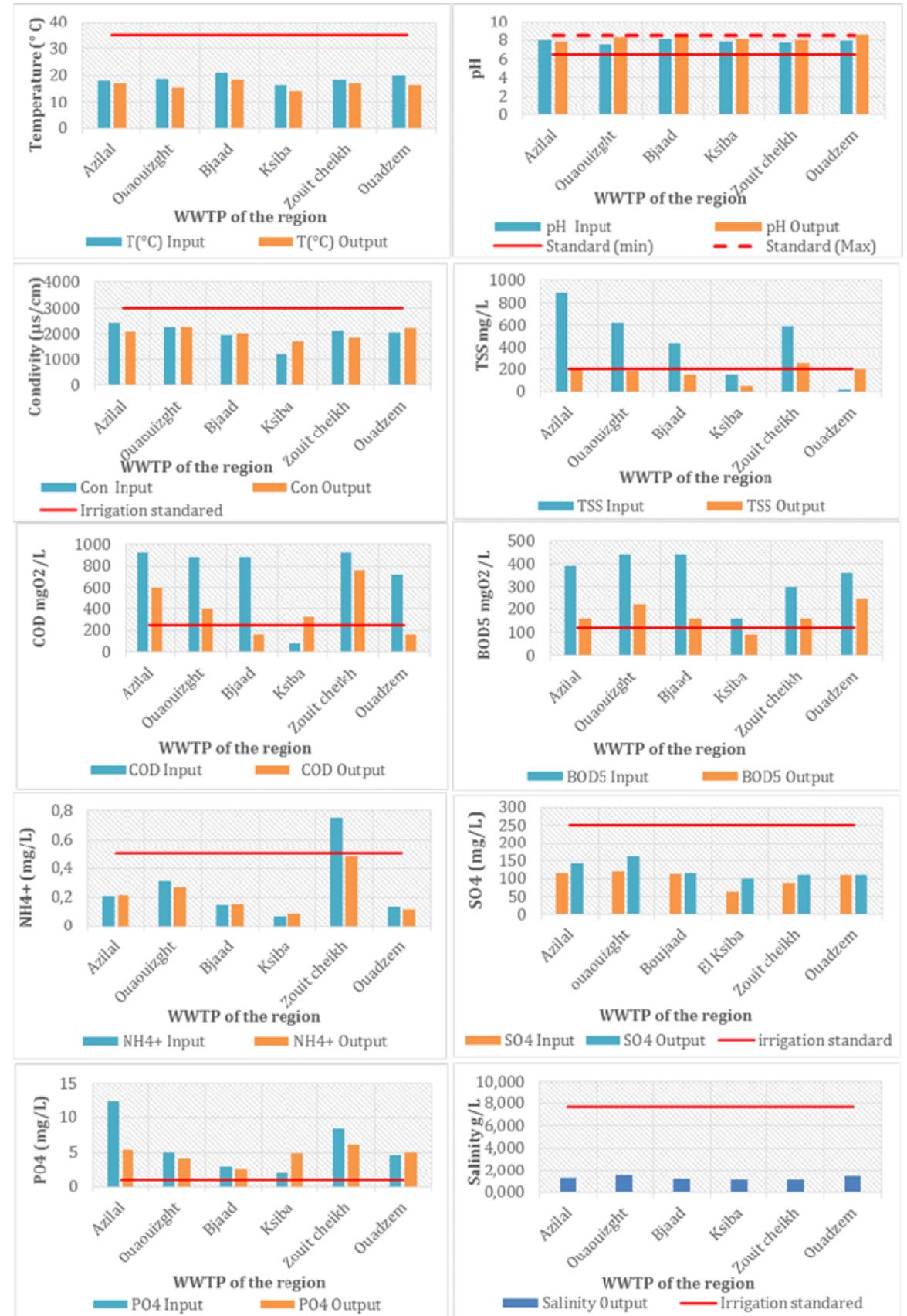

Fig. 2:Physico-chemical and organic analyses results for treated wastewater.

\subsection{Survey results analysis}

Survey results indicate that agricultural practices in BeniMellal-Khenifra region are linked to perennial culture (arboriculture) and annual culture (cereal and market gardening). 
The reuse of treated wastewater in the study area is very varied: the majority of cities are not interested in the reuse of wastewater while others consider it as a reliable and beneficial alternative to irrigation and, at the same time, for agriculture.

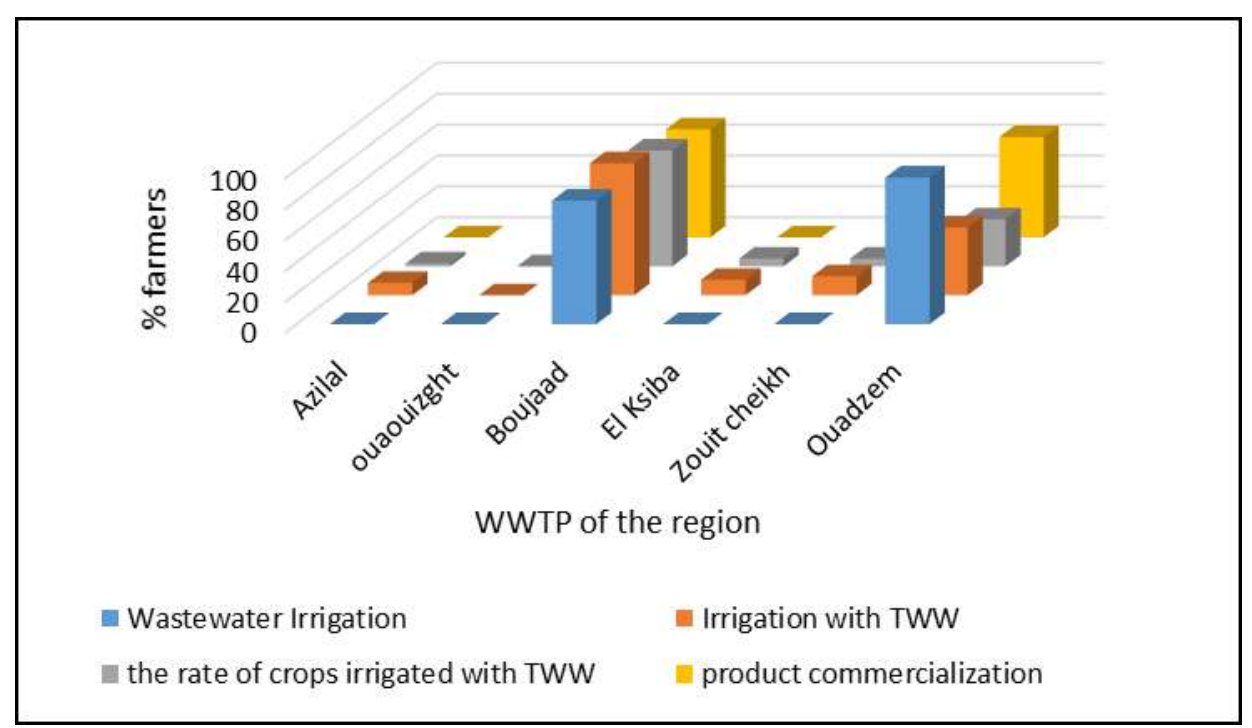

Fig. 3. Results of surveys conducted at the study area level

The information acquired during surveys, field visits, and by comparing analysed samples with Moroccan standards for wastewater intended into irrigation, showed that all WWTPs in the area has the ability to reuse their treated wastewater for irrigation without major negative impacts on the environment.

The classification of WWTPs was done based on surveys and their efficiency history. Results were used to classify the Boujaad wastewater treatment plant as a model treatment plant, because of its performance and experience of reusing treated wastewater in the irrigation of all crops and green spaces in the center of the city. The reuse of wastewater from the Boujaad WWTP has several positive impacts on different aspects, namely: saving water and fertilizers, improving crop yields, improving farming techniques, protecting consumer health and the environment.

\subsection{Satellite images analysis:}

Satellite images were used to infer the contribution of wastewater treatment plants on vegetation cover development at the study area, we used satellite images to identify and characterize the dynamics of the vegetation cover trend observed in the field. A diachronic analysis of images acquired in 2008 (Landsat TM) and in 2018 (Landsat OLI). The classification results are presented in (figure 4) showed the vegetation cover, and land cover variation: 

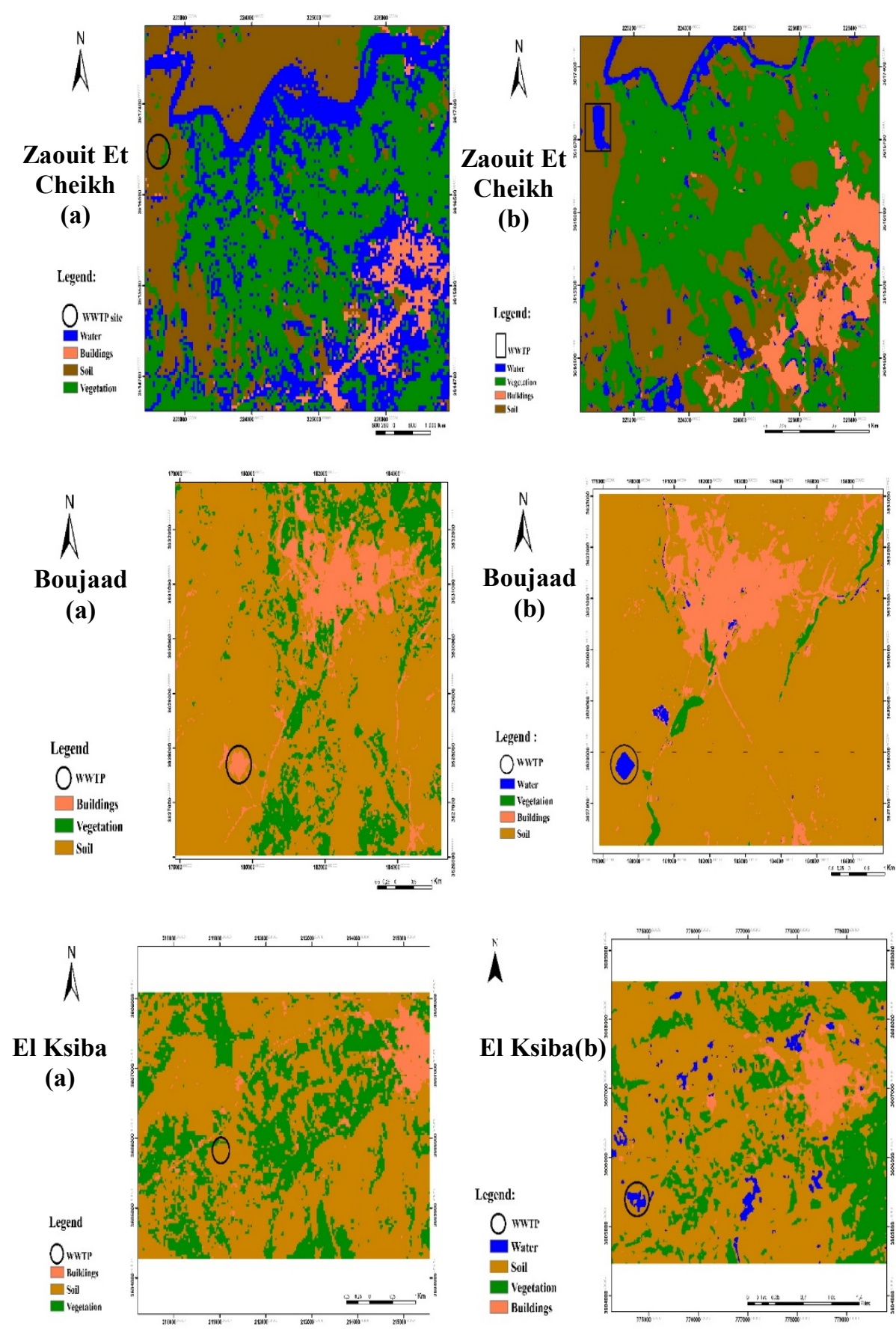


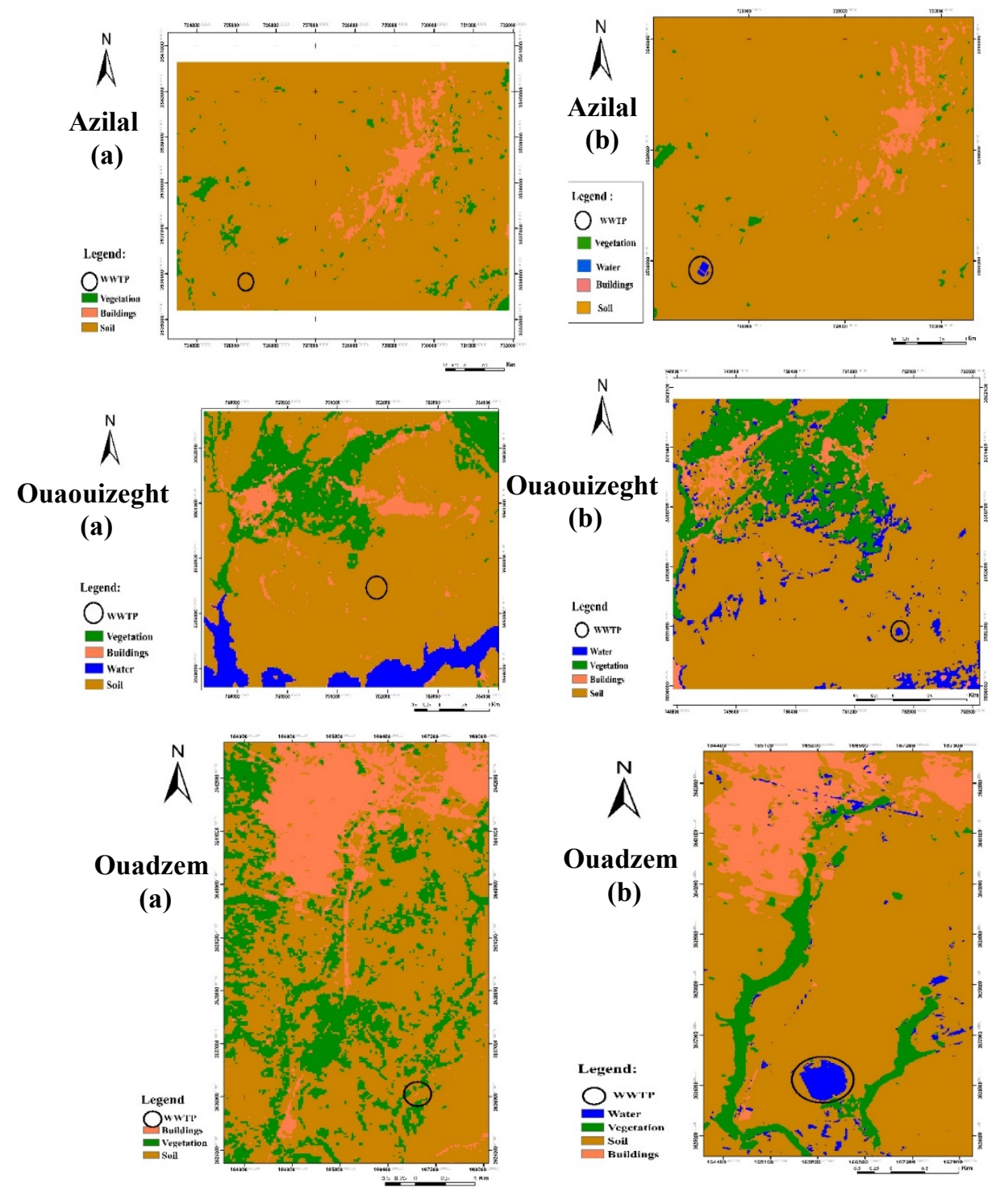

Fig. 4.Land use maps before (a) and after (b) construction of the WWTPs studied

The diachronic study showed that vegetation cover around the WWTPs areas was very important in 2008 (before the existence of WWTPs), possibly because of the diversity of land uses (agricultural and riparian areas). 2008 was a particularly wet year (annual precipitation of $729.14 \mathrm{~mm}$ ), which may explain the density of vegetation found on the satellite images. The images acquired in 2018 (after the construction of WWTPs), show that dense vegetation formations are located mainly in mountain areas, at the edges of watercourses and in plots near WWTPs where irrigation made use of wastewater (ZaouitEchcheik, Boujaad, OuedZem).Sparse crops were found in the irrigated areas by wells. The rest of the region was devoid of vegetation for most of the year due to the low rainfall in 2018 (522.96 mm)[26].The comparison between 2008 and 2018was done having in mind the exceptional precipitation recorded during 2008. Taking into consideration that 2018 has a low quantity of annual precipitation, it was very clear that WWTP were 
improving the vegetation cover near all studied treatment plants, especially for cultivated lands, and irrigated perimeters.

\section{Conclusions}

The studyhighlightedthe importance of WWTP in BeniMellal-Khenifra region (Azilal, Ouaouizeght, ZaouitEchcheikh, El Ksiba, Boujaad and OuedZem) for the agriculture areas, and assessed the physicochemical quality of the treated water. All parameters were in compliance with both national and international regulations on wastewater reuse. Indeed, the performance of the various WWTPs in the study area was appropriate. The BoujaadWWTP was identified as the bestin the study area because it adopts an approach that includes the collection, purification, recovery of treated wastewater, reuse of this water for irrigation and watering of green spaces. Low resolution satellite images were used to evaluate the impacts of WWTP on vegetation. They failed to detect clearly the evidence of the contribution of WWTPs on the vegetation cover and on the hydrographic system, possibly because of their low resolution. On the other hand, field visits and surveys with farmers led to the conclusion that the use of wastewater in the area of irrigation .generated the creation of several cultivated plots. Products cultivated in these plots were marketed locally and regionally without any restrictions.

The authors thank the head laboratory manager at OumEr-Rbia Hydraulic Basin Agency MrAbdelkhalek EL AMRANI IDRISSI, for his technical assistance. Greater appreciation goes to all those responsible personnel and supervisors for WWTP in the BeniMellalKhenifra region, for their help and contributions. We thank Mr Mohamed Baadi, the university driver for his time devoted to all our missions.

\section{References}

1. J. Schilling, K. P. Freier, E. Hertig, et J. Scheffran, Climate change, vulnerability and adaptation in North Africa with focus on Morocco , Agric. Ecosyst. Environ. vol. 156, p. 12-26, août (2012), doi: 10.1016/j.agee.2012.04.021.

2. H. J. Oulidi, A. Fadil, et N. E. Semane,N.E.Eds, Geospatial Technology: Application in Water Resources Management. Springer International Publishing, (2020).

3. J. El Addouli, A. Chahloui, A. Berrahou, A. Chafi, A. Ennabili, andL.Karrouch, Influence de rejets d'eaux usées sur les qualités physicochimique et bactériologique d'eaux utilisées en irrigation, vol. 4, no. 56. (2009).

4. I. Karaoui, A. Arioua, A. E. A. Idrissi, and D. Elhamdouni, Elucidating the mechanisms of water quality deterioration in Oued El Abid River-Morocco-, J. Mater. Environ. Sci., vol. 8, no. 9, pp. 3353-3359, (2017).

5. M. A. Hanjra, J. Blackwell, G. Carr, F. Zhang, and T. M. Jackson, Wastewater irrigation and environmental health: Implications for water governance and public policy, Int. J. Hyg. Environ. Health, vol. 215, no. 3, pp. 255-269, Apr. (2012), doi:10.1016/j.ijheh.2011.10.003.

6. N. Xu, Detecting Coastline Change with All Available Landsat Data over 1986-2015: A Case Study for the State of Texas, USA, Atmosphere, vol. 9, no. 3, p. 107, Mar. (2018), doi: 10.3390/atmos9030107.

7. C. Pipitone, A. Maltese, G. Dardanelli, M. L. Brutto, and G. L. Loggia, Monitoring Water Surface and Level of a Reservoir Using Different Remote Sensing Approaches and Comparison with Dam Displacements Evaluated via GNSS, Remote Sens., vol. 10, no. 2, p. 71, Jan. (2018), doi: 10.3390/rs10010071. 
8. L. Sun and K. Schulz, The Improvement of Land Cover Classification by Thermal Remote Sensing, Remote Sens. vol. 7, no. 7, pp. 8368-8390, Jun. (2015), doi: 10.3390/rs70708368.

9. Office National de l'Eau Potable, «Etude d'impact sur l'environnement, Maroc », p. 126, (2006).

10. C. R. Steinmann, S. Weinhart, et A. Melzer, A combined system of lagoon and constructed wetland for an effective wastewater treatment, Water Res., vol. 37, no 9, p. 2035-2042, (2003), doi: 10.1016/S0043-1354(02)00441-4.

11. H. E. Maynard, S. K. Ouki, and S. C. Williams, Tertiary lagoons: a review of removal mecnisms and performance, Water Res., vol. 33, no 1, p. 1-13, janv. (1999), doi: 10.1016/S0043-1354(98)00198-5.

12. S. Msaad, N. Abbadi, M. Mbarki, S. Rabi, N. Belkhouya, and A. Gamouh, A Study related to the management of medical and pharmaceutical wastes in BeniMellalKhenifra region: BeniMellal city as a case of study, E3S Web Conf., vol. 150, p. 02019, (2020), doi: 10.1051/e3sconf/202015002019.

13. K. Ait Ouhamchich, I. Karaoui, A. Arioua, A. Kasmi, D. Elhamdouni, F.E. Elfiraoui, Z. Arioua, F. Nazi, and N. Nabih,Climate Change Trend Observations in Morocco: Case Study of BeniMellal-Khenifra and Darâa-TafilaltRegions, J. Geosci. Environ. Prot., vol. 06, no 07, Art. no 07, juill.(2018), doi: 10.4236/gep.2018.67003.

14. A. Barakat, A. Hilali, M. E. Baghdadi, and F. Touhami, Landfill site selection with GIS-based multi-criteria evaluation technique. A case study in BeniMellal-Khouribga Region, Morocco, Environ. Earth Sci., vol. 76, no 12, p. 413, juin (2017), doi: 10.1007/s12665-017-6757-8.

15. Direction Générale des CollectivitésLocales, monographie de la région de Béni Mellalkhénifra, Maroc. (2015).

16. Y. Asfers, H. Taouil, A. Amine, S. Elanz, and S. I. Ahmed, Study of Physico-Chemical Quality of the Surface Waters of the Estuary of the Western Basin of the OuedOumErrabia-Morocco, IOSR J. Appl. Chem., vol. 10, no 05, p. 41-49, mai(2017), doi: 10.9790/5736-1005024149.

17. A. Yang, S. Jiang, and H. Deng, A P2P Network Traffic Classification Method Using $S V M$, in 2008 The 9th International Conference for Young Computer Scientists, Hunan, China, Nov. (2008), pp. 398-403, doi: 10.1109/ICYCS.2008.247.

18. J. Rodier, B. Legube, et N. Merlet, Analyse de l'eau 9 e édition. Dunod, Paris, (2009).

19. N. Legros, La réutilisation des eaux usées traitées en irrigation comme incubateur d'un processus de pérennisation et de bonne gouvernance des infrastructures d'assainissement: cas pratique de la station d'épuration de Tidili au Maroc, p. 93, (2017).

20. R. Lal and B. A. Stewart, Soil Water and Agronomic Productivity, 1st Edition. CRC Press, (2012).

21. Z. Muyen, G. A. Moore, et R. J. Wrigley, Soil salinity and sodicity effects of wastewater irrigation in South East Australia, Agric. Water Manag., vol. 99, no 1, p. 33-41, Nov.(2011), doi: 10.1016/j.agwat.2011.07.021.

22. M. E. Mokhtar, M. Chibout, M. Kili, B. EL Mansouri, J. Chao, S.M. EL Kanti, A. Ntarmouchant, and A. Benslimane, Évaluation de l'intrusion saline dans la nappe de Foum El Oued, province de Lâ̂youne, Maroc, Bull. L'Institut Sci. Rabat Sect. Sci. Terre, vol. 40, p. 53-69, (2018). 
23. Arrété $\mathrm{N}^{\circ}$ 1276-01 conjoint du ministre de l'équipement et du ministre chargé de l'aménagement du territoire, de l'urbanisme et de l'habitat et de l'environnement, les normes de qualité des eaux destinées à l'irrigation au Maroc, (oct. 17, 2002).

24. M. Aboelnour and B. A. Engel, Application of Remote Sensing Techniques and Geographic Information Systems to Analyze Land Surface Temperature in Response to Land Use/Land Cover Change in Greater Cairo Region, Egypt, J. Geogr. Inf. Syst., vol. 10, no. 1, Art. no. 1, Jan. (2018), doi: 10.4236/jgis.2018.101003.

25. C. Benmoussa, M. El Yazghi, et S. Mezouar, Arrêté $n^{\circ}$ 1607-06 du 29 Joumada II 1427 portant fixation des valeurs limites spécifiques de rejet applicables aux déversements d'eaux usées des agglomérations urbaines, (juill. 25, 2006).

26. R. Mosteo, M.P. Ormad, P. Goñi, J. Rodríguez-Chueca, A. García, and A. Clavel, Identification of pathogen bacteria and protozoa in treated urban wastewaters discharged in the Ebro River (Spain): water reuse possibilities, Water Sci. Technol., vol. 68, no 3, p. 575-583, août (2013), doi: 10.2166/wst.2013.201. 